\section{Una etnografía del amor digital}

Duportail, Judith. (2019). El algoritmo del amor: un viaje a las entrañas de Tinder. Barcelona: Contra. 179 páginas.

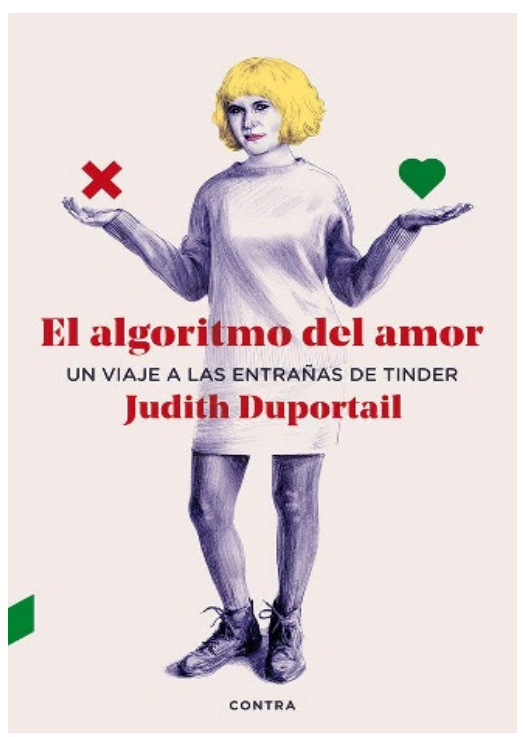

¿Puede una persona encontrar al amor de su vida mediante un aplicativo de citas? Esta interrogante es el centro de la investigación que realiza Judith Duportail (2019) en su primera publicación propia. Mediante el uso de los recursos de la etnografía digital, la autora recorre como usuaria e investigadora los pasos de todos aquellos que buscan el amor -o un sentimiento que se asemeje a elloa través de sus teléfonos celulares mediante el aplicativo de citas y relaciones Tinder.

En el mundo, más de 80 millones de personas tienen una cuenta en Tinder. El éxito de la aplicación parece ser sencillo: lo descargas gratuitamente, creas un perfil con tus mejores fotos, colocas tus gustos y tus preferencias $y$, finalmente, escoges a qué tipo de personas estás buscando. Además, existe una versión pagada de la aplicación que te otorga una mayor probabilidad de escoger a los perfiles más solicitados, así como de conseguir que ellos te tomen en cuenta. Sin embargo, más allá de las elecciones, lo más importante está en el inicio: ¿Cómo es que una aplicación de libre uso genera rentabilidad? Los datos personales de cada usuario son el gran negocio detrás de esta plataforma dedicada a unir parejas.

Duportail (2019) narra su propio viaje y los encuentros con los rostros, labios y mensajes de distintas personas que se contactan con ella en París (Francia) y Berlín (Alemania). A lo largo de los 16 capítulos de El algoritmo del amor. Un viaje a las entrañas de Tinder (2019), la inmersión en primera persona muestra el paso a paso del relacionamiento digital posmoderno. El celular te muestra entre 1 y 5 fotos de alguien, además de los 500 caracteres con los que éste intenta captar tu atención. Si te gusta, deslizas su foto hacia la derecha de la pantalla. Si el futuro, potencial, amante te encuentra en su app y desea conocerte, girará tu foto de la misma forma. Automáticamente, la pantalla de ambos tendrá una alerta de match o coincidencia'. El encuentro por el futuro amor comienza allí.

Este ejercicio simple de elección se repite innumerables veces en cada teléfono celular. Tras cada rechazo (izquierda) o aprobación (derecha), aparece sucesivamente otra fotografía de una nueva persona. La lista parece interminable. La autora descubre, entonces, el éxito de la aplicación: el modelo de recompensa aleatoria utilizado en los tragamonedas genera en los usuarios una expectativa constante por la siguiente jugada. Todos quieren saber si la siguiente vez podrán obtener un premio o no: quizá el amor de su vida todavía no aparece en su pantalla.

Algunas preguntas aparecen alrededor del texto: ¿Cuántas fotos debes deslizar hacia la derecha para encontrar el match de tu vida? ¿Con cuántos match puedes hablar al mismo tiempo para concertar una cita? ¿Cuántas citas debes esperar hasta ratificar que acabas de encontrar el amor? Duportail (2019) se interroga constantemente sobre su propia seguridad para amar y empezar una relación; sin embargo, no deja de pensar en la aceptación de los otros sobre ella misma. Más allá de a quiénes ella pueda elegir, lo importante es también ser elegida, ser seleccionada para la siguiente fase de un concurso donde evaluamos y nos evalúan permanentemente.

¿A cuántos le parecerá atractiva? ¿Cuántos desean salir con ella tras leer la descripción en la que afirma -en broma-que tiene 5 estrellas en BlaBlaCar (una aplicación para viajes en vehículos compartidos)? En el capítulo 13 se descubrirá que una de cada 2 personas que usa Tinder quisiera conocerla. 0 , en otras palabras, tiene un nivel de deseabilidad de 55\%.

Si la identidad, como recuerda Hall (2010), es un relato que se reconstruye constantemente, la identidad de los sujetos que entregan sus datos a una aplicación de citas está asociada directamente a la tasa de éxito que reciban: a esta aprobación que les otorga un nivel de deseabilidad frente a millones de potenciales amores detrás de la pantalla. En la construcción por el propio reconocimiento, la imagen que los otros construyen de uno se ve reducida a una aprobación eliminatoria en la que todo vale con tal de recibir el visto bueno del otro. 
Badiou (2017) destaca que el amor se encuentra amenazado en tiempos de páginas de citas: donde todos buscan una seguridad constante por las coincidencias, por las similitudes, por los lugares comunes que un algoritmo determina como idénticos; el amor se destaca en su inconmensurabilidad como imperfecto, transgresor y revolucionario. En un contexto donde los sujetos tienen poco tiempo para conocer a los otros y experimentar el ensayo-error constante, la vergüenza y la transición de la identificación-diferenciación en relación con ese otro; el deseo por disminuir los riesgos y dejar la elección del amor de tu vida en las redes de una app nos tintinea constantemente en la pantalla.

Duportail (2019) descubre, sin embargo, que el algoritmo del amor no se ejerce libremente. Todos los usuarios no son tus posibles amores y tampoco lo son aquellos que tú pareces desear. El algoritmo que determina el éxito de tu siguiente cita reproduce en cada fase "el modelo patriarcal de las relaciones heterosexuales" (p.156).

El gran descubrimiento del libro no acaba en las 802 páginas que Tinder le entrega a la autora con todos los datos que tiene de ella desde el día en que se registró gratuitamente en el aplicativo. Las elecciones que hacen los usuarios acerca del siguiente amor parecen no aparecer libremente ni determinados por sus simples elecciones iniciales: el algoritmo construye un imaginario del posible amor perfecto en el que el nulo riesgo por la diferencia social, económica e ideológica está atravesado por los roles de género machistas:

Solo a modo de ejemplo, imaginemos que Harry y Sally son dos usuarios registrados [...]. En este ejemplo, Harry tiene diez años más que Sally, gana US\$10.000 más que ella al año y tiene un máster, mientras que Sally solo tiene un grado. A pesar de las diferencias, el servidor atribuirá al perfil de Sally una puntuación alta que aumentará sus posibilidades de aparecer en la lista de resultados de Harry. [...] Sin embargo, si es Sally quien hace la búsqueda y el servidor evalúa el perfil de Harry, se puede obtener un resultado distinto. Así, si es Sally quien tiene diez años más, gana US\$10.000 más y tiene un máster, mientras que Harry solo tiene un grado, el servidor atribuirá una puntuación baja al perfil de Harry, con lo que tendrá menos posibilidades de aparecer en la lista de resultados de Sally (Duportail, 2019, pp.55-56).

Finalmente, el objeto de estudio de Duportel no solo es Tinder -la empresa que generó ingresos por 1.000 millones de euros en 2019-, sino las propias relaciones que se construyen a partir del reconocimiento de un amor escogido para ti a partir de algoritmos supuestamente libres, pero que reproducen esquemas sociales e ideológicos.

En la búsqueda por la siguiente cita que te lleve a no abrir la app nunca más, los usuarios entregan sus da- tos personales gratuitamente a una empresa lista para identificar tus emociones, clasificar tus gustos y conocer tus deseos, incluso los más perversos. Cada vez que navegas por ella, tus pasos quedan grabados y son almacenados, distribuidos y clasificados. El costo del amor ideal es la entrega completa de una huella en el mundo digital. Este libro es importante porque nos ayuda a tomar consciencia de ello y a conocer los alcances de la plataformización de las relaciones sociales, incluso las íntimas.

\section{Miguel Angulo-Giraldo}

Universidad Científica del Sur, Lima, Perú

angulo.runåagmail.com

\section{Nota}

1. Esta denominación es la que utiliza la plataforma para dar cuenta de que dos usuarios han coincidido en aceptarse mutuamente para conocerse.

\section{Referencias}

Badiou, A. (2017). Elogio del amor. Asociación Civil Mírame Bien.

Hall, S. (2010). Sin garantías. Trayectorias y problemáticas en estudios culturales. Instituto de estudios sociales y culturales Pensar. 